\title{
Does the length of the biliary limb influence medium-term laboratory remission of type 2 diabetes mellitus after Roux-en-Y gastric bypass in morbidly obese patients?
}

\author{
Łukasz Kaska, Jarek Kobiela, Monika Proczko, Tomasz Stefaniak, Zbigniew Śledziński \\ Department of General, Endocrine and Transplant Surgery, Medical University of Gdansk, Poland
}

Videosurgery Miniinv 2014; 9 (1): 31-39

DOI: $10.5114 /$ wiitm.2014.40383

\begin{abstract}
Introduction: The Roux-en-Y gastric bypass (RYGB) is an effective treatment of morbid obesity leading to type 2 diabetes mellitus (T2DM) resolution. However, evidence demonstrates that standard limb lengths can have a limited impact on long-term weight loss and durable T2DM remission.

Aim: The authors evaluated the impact of biliary limb $(B L)$ length on the T2DM laboratory markers in 2-year follow-up.

Material and methods: The data of 93 obese patients with T2DM who underwent RYGB between 2008 and 2010 were collected from prospectively designed database. The length of BL was standard in one group of 51 patients $(S-B L: 50-75 \mathrm{~cm})$ and longer in another group of 42 patients $(L-B L: 100-150 \mathrm{~cm})$. The laboratory parameters defining T2DM remission - fasting plasma glucose (FPG) and glycosylated hemoglobin $\left(\mathrm{HbA}_{1 \mathrm{c}}\right)$ - were measured 3, 6, 12 and 24 months after surgery.

Results: The average level of FPG and $H b A_{1 c}$ remained non-diabetic 24 months after the RYGB in both groups. A statistical difference was not observed in direct $F P G, H b A_{1 c}, \triangle F P G$ and $\triangle H b A_{1 c}$ comparisons at any follow-up point. However, a significantly higher proportion of patients in $L-B L$ than in S-BL reached the laboratory remission criteria without anti-diabetic medicaments. Additional analysis revealed a strong correlation between the measured T2DM parameters and length of the common limb $(C L)$ in both groups.

Conclusions: A longer $B L$ can intensify the anti-diabetic effect of $R Y G B$. The length of $C L$ rather than $B L$ influences the medium-term T2DM remission. Long-term observation is needed to fully assess whether introduced technical aspects of RYGB provide a durable effect of T2DM resolution.
\end{abstract}

Key words: type 2 diabetes mellitus, Roux-en-Y gastric bypass, biliary limb, laboratory remission.

\section{Introduction}

The epidemic of obesity is associated with a rapid growth of type 2 diabetes mellitus (T2DM). It is estimated that over 300 million people will be affected with T2DM by the year 2025 [1, 2]. This stimulates the authorities of the health care systems to search for effective treatment of both obesity and T2DM. Bariatric surgery, particularly methods excluding the duodenum and the proximal part of the jejunum, represents the most effective treatment of morbid obesity [3-8]. Several recent publications have demonstrated the influence of Roux-en-Y gastric bypass (RYGB) and biliopancreatic diversion (BPD) on 
glycemia control [9-11]. Therefore it seems surgery should be considered as the most effective method of T2DM management. Roux-en- $Y$ gastric bypass is the most frequently performed bariatric procedure worldwide and is accepted by many as the gold standard [12]. Although this method leads to substantial laboratory remission of T2DM in as many as 60-90\% of cases and in consequence reduces the clinical presentations of the disease, its curative potential will be evaluated in long-term observations $[8,13,14]$. The large number of RYGB modifications demonstrates the limitation of the procedure originally introduced by Mason and Ito [15, 16]. Durable effectiveness of RYGB seems to be hampered mainly by the weight regain, resulting in the restoration of comorbidities including recurrence of glucose intolerance [17]. The reported higher impact of BPD than RYGB on both long-term weight loss and permanent T2DM resolution does not translate into more frequent usage of the procedure $[10,18]$. Biliopancreatic diversion still remains less appealing and technically more demanding, with potentially higher risk of early and late adverse events. However, its highest effec-

Table I. Profile of patients

\begin{tabular}{|c|c|c|}
\hline Parameter & S-BL & L-BL \\
\hline Number of cases & 51 & 42 \\
\hline LRYGB/RYGB (ratio) & $31 / 10(1.55)$ & $34 / 8(1.33)$ \\
\hline Male/female (ratio) & $19 / 32(0.59)$ & $26 / 42(0.62)$ \\
\hline Average age [years] & $46.2 \pm 5.67$ & $47.8 \pm 5.81$ \\
\hline Patients on insulin [\%] & $14 / 51(27.5)$ & $13 / 42(30.9)$ \\
\hline $\begin{array}{l}\text { Average disease duration } \\
\text { [years] }\end{array}$ & $6.1 \pm 0.96$ & $6.8 \pm 1.07$ \\
\hline Average $\mathrm{HbA}_{1 c}[\%]$ & $8.6 \pm 0.84$ & $8.9 \pm 1.32$ \\
\hline Average FPG [mg\%] & $192.3 \pm 40.67$ & $188.6 \pm 46.58$ \\
\hline $\begin{array}{l}\text { Average C-peptide level } \\
{[\mu \mathrm{g} / \mathrm{l}]}\end{array}$ & $2.4 \pm 0.27$ & $2.6 \pm 0.31$ \\
\hline Average BMI $\left[\mathrm{kg} / \mathrm{m}^{2}\right]$ & $43.3 \pm 5.67$ & $45.1 \pm 5.46$ \\
\hline Average size of pouch [ml] & $35.8 \pm 5.91$ & $36.2 \pm 5.66$ \\
\hline $\begin{array}{l}\text { Average length of alimentary } \\
\operatorname{limb}[\mathrm{cm}]\end{array}$ & $157.9 \pm 50.11$ & $151.4 \pm 27.97$ \\
\hline $\begin{array}{l}\text { Average length of biliary } \\
\operatorname{limb}[\mathrm{cm}]\end{array}$ & $68.8 \pm 8.48$ & $133.2 \pm 17.50$ \\
\hline $\begin{array}{l}\text { Average length of common } \\
\text { limb [cm] }\end{array}$ & $237 \pm 59.75$ & $193.5 \pm 56.72$ \\
\hline
\end{tabular}

tiveness of available bariatric options stimulates surgeons to modify RYGB using BPD metabolic assumptions. This is achieved by creating different lengths of alimentary (AL), biliary (BL) and finally the common limb (CL). Stefanidis et al. in an evidence-based review presented considerable variability of $A L$ and $B L$ length preferred by different bariatric centers in the range $35-250 \mathrm{~cm}$ (average $110 \mathrm{~cm}$ ) and $10-250 \mathrm{~cm}$ (average $48 \mathrm{~cm}$ ), respectively [16]. Although most surgeons use body mass index (BMI) as a decisive criterion to determine the limb lengths, much variability is observed even for patients with the same BMI [16]. Apart from the already widely acknowledged hybrid mechanism of RYGB, several endocrine hypotheses have been proposed in the most recent studies [19-21]. Therefore, the modern approach to bariatric solutions is not only limited to searching for the best balance between the degree of restriction, malabsorption and patients' safety [19-21]. The foregut and hindgut hypotheses after RYGB described by Rubino and Cummings explain the hormonal and metabolic benefits of bypassing the duodenum and proximal part of the jejunum, and accelerating the passage of undigested food to the distal intestine, all resulting in better glycemic control [13, 21, 22].

\section{Aim}

The authors, inspired by the importance of the hormonal hypothesis and based on their own longterm observation of BPD patients, modified the RYGB procedure by extending the biliary limb in order to evaluate its clinical effectiveness in T2DM resolution.

\section{Material and methods}

The data of 93 morbidly obese patients (BMI $35.2-55 \mathrm{~kg} / \mathrm{m}^{2}$, mean $44.2 \mathrm{~kg} / \mathrm{m}^{2}$, SD $5.52 \mathrm{~kg} / \mathrm{m}^{2}$ ) with T2DM who underwent RYGB between October 2008 and November 2010 were retrieved from a prospectively designed database. The standard short biliary limb (S-BL) was used in 51 cases. The majority of 42 patients with extended $\mathrm{BL}(\mathrm{L}-\mathrm{BL})$ were operated on in 2010. The number of the cases included in the study was determined by the completion of a 2-year observation period with fixed follow-up visits 3, 6, 12 and 24 months postoperatively. Group characteristics are summarized in Table I. The preoperative period lasted 3-4 months and was based on cooperation with a psychologist, dietician, endocrinologist and bariatric surgeons. During this period 
at least 2 meetings with each of the specialists were obligatory to ensure optimal general condition of the patients at the time of surgery and to prepare them to follow the postoperative dietary requirements. During the follow-up visits, among the basic metabolic tests, the most significant markers of glycemia control acknowledged by leading diabetes associations were assayed - glycosylated hemoglobin $\left(\mathrm{HbA}_{1 \mathrm{c}}, \%\right)$ and fasting plasma glucose (FPG, $\left.\mathrm{mg} / \mathrm{dl}\right)$. The BMI calculated during the initial preoperative visit was used as baseline. In all cases, the preoperative $\mathrm{HbA}_{1 \mathrm{c}}$ and FPG were determined. In addition, the use of antidiabetic agents was noted, as well as the duration of the disease.

All patients were qualified for RYGB. Fifty-five of them underwent a laparoscopic procedure (LRYGB). Regardless of the approach, the technical aspects of the procedures were the same. The size of the pouch was measured during the obligatory methylene blue test and ranged from $30 \mathrm{ml}$ to $40 \mathrm{ml}$ (average $36.01 \mathrm{ml}$, SD $5.79 \mathrm{ml}$ ). Because of the variable individual length of the small intestine $(325-650 \mathrm{~cm}$, average $470.9 \mathrm{~cm}$, SD $108.23 \mathrm{~cm}$ ), the total length was routinely measured before preparing the jejuno-jejunal anastomosis to reduce the risk of harmful malabsorption. The common limb was not shorter than $150 \mathrm{~cm}$. The length of separated loops was basically adjusted to the patients' BMI; however, in some cases the intraoperative anatomical conditions defined the site of the intestinal anastomosis. The intraoperative measurement was carried out on the stretched bowel in the way used by the authors from the beginning of the bariatric activity. The anastomosis was performed after the exclusion of 50-75 $\mathrm{cm}$ of the biliary limb (average $68.8 \mathrm{~cm}, S D 8.48 \mathrm{~cm}$ ) in the S-BL group and 100-150 cm (average $130.5 \mathrm{~cm}, S D 17.50 \mathrm{~cm}$ ) in the L-BLgroup, with alimentary limb values of $100-200 \mathrm{~cm}$ (average $157.9 \mathrm{~cm}$, SD $50.11 \mathrm{~cm}$ ) and 75-200 cm (average $151.4 \mathrm{~cm}, \mathrm{SD} 27.97 \mathrm{~cm}$ ) in S-BL and L-BL, respectively.

The follow-up visits were organized by a multidisciplinary team at the presented time points. The postoperative nutritional program arranged by the dieticians to prevent potential malnutrition was obligatory as after any bariatric procedures. The diabetologist determined the necessity of administration of anti-diabetic medications. The assays of the glycemia markers were all performed in the same laboratory.

The authors present the results of postoperative average change of $\mathrm{HbA}_{1 \mathrm{c}}, \mathrm{FPG}$ and loss of BMI 3, 6,
12 and 24 months postoperatively, comparing group $\mathrm{S}-\mathrm{BL}$ with group $\mathrm{L}-\mathrm{BL}$. The percentage of patients who met the non-diabetic laboratory norm without anti-diabetic medications at postoperative check points has been presented in a separate specification.

The criteria used for T2DM remission were The National Institutes of Health guidelines: normal FPG $\leq 100 \mathrm{mg} \%$ and "nondiabetic" range of $\mathrm{HbA}_{1 \mathrm{c}} 4.0$ $6.0 \%[23-25]$.

The spectrum, methodology and assumptions of the study were accepted by the local bioethical committee of the Medical University of Gdansk, Poland.

\section{Statistical analysis}

Statistical analysis was performed using Statistica software. $T$-tests were used for comparisons of the groups at individual follow-up points. Pearson coefficient of correlation was used for the analysis of the length of $\mathrm{CL}$.

\section{Results}

All 93 patients were followed up according to the established schedule. Gastrointestinal leak as the most serious complication was observed in 2 patients in the S-BL group. The first leakage was diagnosed in the site of the staple line of the remnant stomach and required reoperation and closure on the second postoperative day. The stenosis of the pouch-jejunal anastomosis 12 months after the procedure was the reason for late pouch-cutaneous fistula in another case. Endoscopic dilatation of the anastomosis and self-expanding covered stent implantation with intense nutrition for 8 weeks was an effective treatment. In the L-BL group 1 patient required re-operation after 3 months of insufficient conservative treatment of the low secreting pouch-cutaneous fistula.

Control endoscopy 1 year after RYGB demonstrated ulceration in the site of anastomosis in 3.9\% and $4.8 \%$ of the patients in S-BL and L-BL groups respectively, which was successfully treated conservatively. Severe protein calorie malnutrition clinically expressing mainly with prolonged loose stools and lower extremities edema was laboratory proven in 1 patient 12 months after L-BL RYGB. Improvement of the nutritional parameters followed by symptoms' alleviation was observed 6 months later after intense dietary treatment.

The postoperative complications are listed in Table II with the most common adverse events reported during the postoperative visits. 
Table II. Serious complications and adverse events

\begin{tabular}{|lcc|}
\hline Parameter & S-BL & L-BL \\
\hline Number of cases & 51 & 42 \\
\hline Gastrointestinal leak/fistula (\%) & $2(3.9)$ & $1(2.3)$ \\
\hline Anastomotic stenosis & $1(2)$ & 0 \\
\hline Ulcer in anastomosis & $2(3.9)$ & $2(4.8)$ \\
\hline Wound infection & $2(3.9)$ & $2(4.8)$ \\
\hline Incisional hernia & $1(2)$ & $1(2.4)$ \\
\hline Anemia Hb < 11 g\% & $1(2)$ & $2(2.4)$ \\
\hline Pneumonia & $1(2)$ & 0 \\
\hline Hypoglycemic episode & $22(43.1)$ & $20(47.6)$ \\
\hline Reoperation & $2^{*}(3.9)$ & $2^{\star}(4.8)$ \\
\hline Endoscopic intervention & $2^{\#(3.9)}$ & 0 \\
\hline Intense conservative treatment & $2^{\wedge}(3.9)$ & $3^{\wedge}(7.1)$ \\
\hline Extensive vomiting & $1(2)$ & 0 \\
\hline Dumping & $3(5.9)$ & $3(7.1)$ \\
\hline Reflux symptoms & $1(2)$ & 0 \\
\hline $\begin{array}{l}\text { Prolonged diarrhea } \\
\text { ( 6 months postop.) }\end{array}$ & $1(2)$ & $2(4.8)$ \\
\hline Severe malnutrition & 0 & $1(2.4)$ \\
\hline
\end{tabular}

*including one hernia repair in each group, one reoperation in each group due to leakage; "dilatation of the anastomosis, stenting of the pouch fistula $\wedge 2$ cases in each group due to hypoglycemic episode, parenteral nutrition in 1 case with fistula in L-BL group
More than $40 \%$ of the patients regardless of the $\mathrm{BL}$ length reported clinical symptoms of hypoglycemic episodes, but in only 2 patients, who required intensive medical treatment, was the accidental glucose level below $50 \mathrm{mg} \%$.

Early laboratory remission of T2DM was observed in some of the patients from both groups. In the vast majority of these patients FPG level lower than $100 \mathrm{mg} \%$ was observed after the surgery while they were still in hospital. A statistical difference was not observed in direct FPG, $\mathrm{HbA}_{1 \mathrm{c}}, \triangle \mathrm{FPG}$ and $\triangle \mathrm{HbA}_{1 \mathrm{c}} \mathrm{com}$ parisons at any follow-up point (Table III, Figures 1 and 2). However, a significantly higher percentage of patients in the L-BL group reached the laboratory remission criteria for both DM parameters at all follow-up points (Table IV, Figure 3).

The results of the diabetic parameters 1 year and 2 years postoperatively demonstrated the stabilization of the downward trend with minimal T2DM restoration tendency at the last follow-up point in the $\mathrm{S}-\mathrm{BL}$ group (in 3/51 patients $\mathrm{HbA}_{1 \mathrm{c}}$ increased above the non-diabetic level). About $80 \%$ of all cases presented $\mathrm{HbA}_{1 \mathrm{c}}$ and FPG below or equal to the threshold established as non-diabetic.

The average level of $\mathrm{HbA}_{1 \mathrm{c}}$ and $\mathrm{FPG}$ remained nondiabetic 24 months after the RYGB in both studied groups. Loss of BMI did not significantly differ between the studied S-BL and L-BL groups (Table V, Figure 4). The dynamics of change in both diabetic markers observed in all patients after RYGB parallel the change of BMI.

Table III. Average FPG and $\mathrm{HbA}_{1 \mathrm{c}}$ level

\begin{tabular}{|c|c|c|c|c|c|c|c|c|c|c|}
\hline \multirow[t]{2}{*}{ Parameter } & \multicolumn{2}{|c|}{ Preop. } & \multicolumn{2}{|c|}{3 months } & \multicolumn{2}{|c|}{6 months } & \multicolumn{2}{|c|}{12 months } & \multicolumn{2}{|c|}{24 months } \\
\hline & S-BL & L-BL & S-BL & L-BL & S-BL & L-BL & S-BL & L-BL & S-BL & L-BL \\
\hline $\mathrm{FPG}[\mathrm{mg} / \mathrm{dl}]$ & $\begin{array}{c}188.6 \\
\pm 40.67\end{array}$ & $\begin{array}{c}192.3 \\
\pm 46.58\end{array}$ & $\begin{array}{l}108.8 \\
\pm 21.15\end{array}$ & $\begin{array}{c}100.6 \\
\pm 18.88\end{array}$ & $\begin{array}{c}97.2 \\
\pm 15.19\end{array}$ & $\begin{array}{r}90.6 \\
\pm 10.57\end{array}$ & $\begin{array}{c}96.6 \\
\pm 13.01\end{array}$ & $\begin{array}{c}92.2 \\
\pm 11.14\end{array}$ & $\begin{array}{c}99.8 \\
\pm 12.89\end{array}$ & $\begin{array}{c}93.4 \\
\pm 11.11\end{array}$ \\
\hline Value of $p$ & \multicolumn{2}{|c|}{0.833} & \multicolumn{2}{|c|}{0.307} & \multicolumn{2}{|c|}{0.211} & \multicolumn{2}{|c|}{0.365} & \multicolumn{2}{|c|}{0.173} \\
\hline$\Delta \mathrm{FPG}(\%)$ & 0 & 0 & $\begin{array}{c}-42.3 \\
\pm 13.72\end{array}$ & $\begin{array}{l}-47.7 \\
\pm 16.15\end{array}$ & $\begin{array}{r}-48.5 \\
\pm 12.38\end{array}$ & $\begin{array}{r}-52.9 \\
\pm 13.05\end{array}$ & $\begin{array}{l}-48.8 \\
\pm 12.95\end{array}$ & $\begin{array}{c}-51.7 \\
\pm 14.62\end{array}$ & $\begin{array}{c}-47.1 \\
\pm 12.77\end{array}$ & $\begin{array}{c}-51.4 \\
\pm 14.17\end{array}$ \\
\hline Value of $p$ & \multicolumn{2}{|c|}{-} & \multicolumn{2}{|c|}{0.707} & \multicolumn{2}{|c|}{0.726} & \multicolumn{2}{|c|}{0.931} & \multicolumn{2}{|c|}{0.744} \\
\hline $\mathrm{HbA}_{1 c}(\%)$ & $\begin{array}{c}8.6 \\
\pm 0.84\end{array}$ & $\begin{array}{c}8.9 \\
+1.32\end{array}$ & $\begin{array}{c}6.2 \\
\pm 041\end{array}$ & $\begin{array}{c}6 \\
\pm 0.19\end{array}$ & $\begin{array}{c}5.8 \\
\pm 0.44\end{array}$ & $\begin{array}{c}5.6 \\
\pm 0.38\end{array}$ & $\begin{array}{c}5.7 \\
\pm 0.51\end{array}$ & $\begin{array}{c}5.4 \\
\pm 0.48\end{array}$ & $\begin{array}{c}5.9 \\
\pm 0.48\end{array}$ & $\begin{array}{c}5.4 \\
\pm 0.50\end{array}$ \\
\hline Value of $p$ & \multicolumn{2}{|c|}{0.413} & \multicolumn{2}{|c|}{0.099} & \multicolumn{2}{|c|}{0.174} & \multicolumn{2}{|c|}{0.130} & \multicolumn{2}{|c|}{0.163} \\
\hline$\Delta \mathrm{HbA}_{1 \mathrm{c}}(\%)$ & 0 & 0 & $\begin{array}{l}-27.9 \\
\pm 7.88\end{array}$ & $\begin{array}{l}-30.2 \\
\pm 10.54\end{array}$ & $\begin{array}{r}-32.5 \\
\pm 8.52\end{array}$ & $\begin{array}{r}-34.9 \\
\pm 12.84\end{array}$ & $\begin{array}{l}-33.7 \\
\pm 9.90\end{array}$ & $\begin{array}{c}-39.3 \\
\pm 14.32\end{array}$ & $\begin{array}{l}-31.4 \\
\pm 9.84\end{array}$ & $\begin{array}{r}-39.3 \\
\pm 14.80\end{array}$ \\
\hline Value of $p$ & \multicolumn{2}{|c|}{ - } & \multicolumn{2}{|c|}{0.707} & \multicolumn{2}{|c|}{0.778} & \multicolumn{2}{|c|}{0.933} & \multicolumn{2}{|c|}{0.873} \\
\hline
\end{tabular}




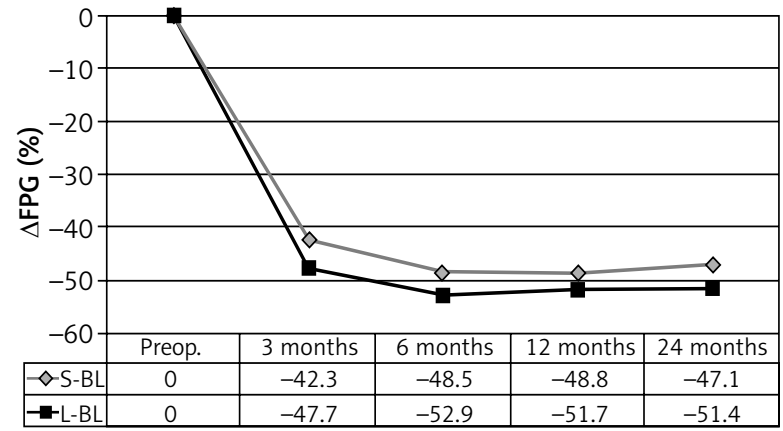

Figure 1 . Change in average FPG level

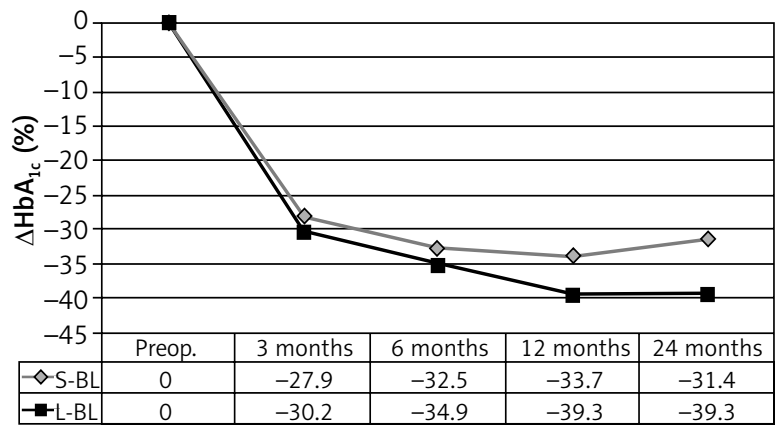

Figure 2. Change in average $\mathrm{HbA}_{1 \mathrm{c}}$ level

Table IV. Percentage of patients in laboratory T2DM remission (without anti-diabetic medications)

\begin{tabular}{|c|c|c|c|c|c|c|c|c|}
\hline & \multicolumn{8}{|c|}{$\%$ Patients } \\
\hline & \multicolumn{2}{|c|}{3 months } & \multicolumn{2}{|c|}{6 months } & \multicolumn{2}{|c|}{12 months } & \multicolumn{2}{|c|}{24 months } \\
\hline & S-BL & L-BL & S-BL & L-BL & S-BL & L-BL & S-BL & L-BL \\
\hline FPG $<100 \mathrm{mg} \%$ & $\begin{array}{c}20 / 51 \\
(35.3 \%)\end{array}$ & $\begin{array}{l}24 / 42 \\
(57.1 \%)\end{array}$ & $\begin{array}{c}35 / 51 \\
(68.6 \%)\end{array}$ & $\begin{array}{c}36 / 42 \\
(85.7 \%)\end{array}$ & $\begin{array}{c}39 / 51 \\
(76.5 \%)\end{array}$ & $\begin{array}{c}40 / 42 \\
(95.2 \%)\end{array}$ & $\begin{array}{c}37 / 51 \\
(72.5 \%)\end{array}$ & $\begin{array}{c}39 / 42 \\
(92.9 \%)\end{array}$ \\
\hline Value of $p$ & \multicolumn{2}{|c|}{0.018} & \multicolumn{2}{|c|}{0.028} & \multicolumn{2}{|c|}{0.009} & \multicolumn{2}{|c|}{0.007} \\
\hline $\mathrm{HbA}_{1 \mathrm{c}}<6 \%$ & $\begin{array}{c}21 / 51 \\
(41.2 \%)\end{array}$ & $\begin{array}{l}26 / 42 \\
(61.9 \%)\end{array}$ & $\begin{array}{c}37 / 51 \\
(72.6 \%)\end{array}$ & $\begin{array}{c}37 / 42 \\
(88.1 \%)\end{array}$ & $\begin{array}{c}41 / 51 \\
(80.4 \%)\end{array}$ & $\begin{array}{c}40 / 42 \\
(95.2 \%)\end{array}$ & $\begin{array}{c}38 / 51 \\
(74.5 \%)\end{array}$ & $\begin{array}{c}40 / 42 \\
(95.2 \%)\end{array}$ \\
\hline Value of $p$ & \multicolumn{2}{|c|}{0.023} & \multicolumn{2}{|c|}{0.038} & \multicolumn{2}{|c|}{0.018} & \multicolumn{2}{|c|}{0.005} \\
\hline
\end{tabular}

Table V. Loss of BMI

\begin{tabular}{|c|c|c|c|c|}
\hline \multirow[t]{2}{*}{ Parameter } & \multicolumn{4}{|c|}{ Loss of BMI } \\
\hline & 3 months & 6 months & 12 months & 24 months \\
\hline S-BL & $-6.3 \pm 1.98(-14.5 \%)$ & $-10.2 \pm 4.54(-23.6 \%)$ & $-12.8 \pm 4.68(-29.6 \%)$ & $-12 \pm 5.36(-27.7 \%)$ \\
\hline L-BL & $-8 \pm 2.67(-17.7 \%)$ & $-12.5 \pm 2.73(-27.7 \%)$ & $-16.1 \pm 3.13(-35.7 \%)$ & $-17.3 \pm 4.18(-38.4 \%)$ \\
\hline Value of $p$ & 0.349 & 0.331 & 0.270 & 0.154 \\
\hline
\end{tabular}

Additional analysis revealed a statistically significant strong or very strong correlation between the measured T2DM parameters' average values and length of $\mathrm{CL}$ at all follow-up points. There was also a statistically significant strong or very strong negative correlation between the measured T2DM parameters' $\Delta s$ and the length of $C L$ (Table $\mathrm{VI}$ ).

\section{Discussion}

In the face of the global growing burden of T2DM, both the patients afflicted with the disease and the physicians committed to the treatment await with hope the results of modern potentially sufficient therapy. Although bariatric surgery was designed primarily to facilitate weight loss, numerous studies present its exceptional high effectiveness in improving obesity-related comorbidities [6-9, 26]. In 1995, Pories et al. demonstrated long-term results of more

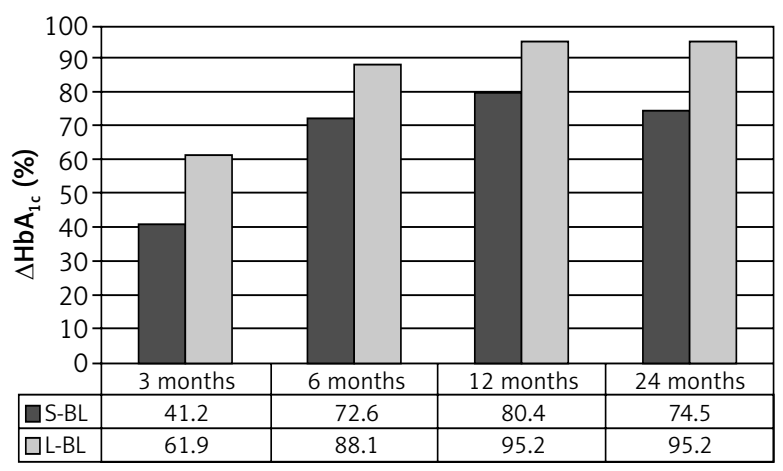

Figure 3. Percentage of patients with $\mathrm{HbA}_{1 \mathrm{c}} \leq 6 \%$ 
Table VI. Correlation between length of $\mathrm{CL}$ and laboratory markers of T2DM

\begin{tabular}{|lcccc|}
\hline Parameter & 3 months & 6 months & 12 months & 24 months \\
\hline $\mathrm{HbA}_{1 \mathrm{c}}(\%)$ & $r=0.48$ & $r=0.76$ & $r=0.86$ & $r=0.81$ \\
\hline$\Delta \mathrm{HbA}_{1 \mathrm{c}}(\%)$ & $r=-0.74$ & $r=-0.77$ & $r=-0.78$ & $r=-0.75$ \\
\hline FPG [mg/dl] & $r=0.42$ & $r=0.52$ & $r=0.68$ & $r=0.65$ \\
\hline$\Delta \mathrm{FPG}(\%)$ & $r=-0.77$ & $r=-0.78$ & $r=-0.79$ & $r=-0.79$ \\
\hline
\end{tabular}

All correlations were statistically significant with $p<0.05$

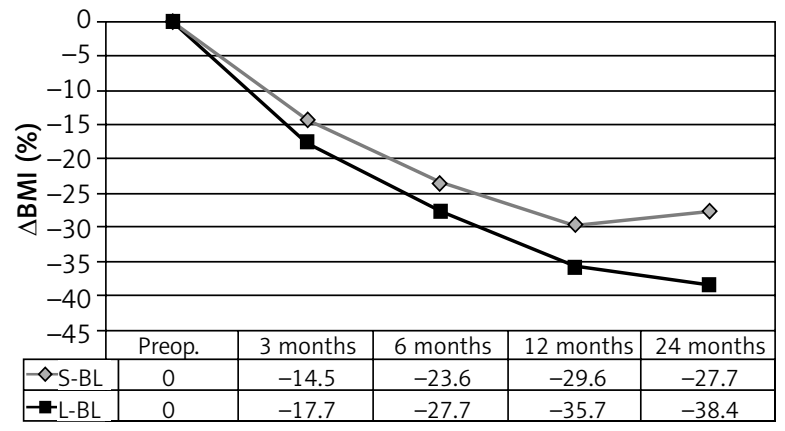

Figure 4. Change in average BMI

than 600 obese patients who underwent RYGB with a follow-up period of 14 years [14]. Eighty-three percent of these individuals experienced durable normoglycemia without anti-diabetic medications. Even more impressive effects of bariatric treatment were published by Scopinaro et al. after BPD [18]. The results recently published in "New England Journal of Medicine" of direct comparison of best available conservative vs. surgical treatment (sleeve gastrectomy, RYGB and BPD) in T2DM remission revealed the distinct advantage of surgery bypassing the duodenum and proximal jejunum in up to 2 years observation [9, 10]. Though gastric bypass is recognized by many as the gold standard of bariatric procedures, its initial model introduced by Mason and Ito was modified over the years in the search for long-term improvement of weight loss and durable resolution of related comorbidities $[12,16]$. The definition of RYGB as a hybrid restrictive and malabsorptive procedure seemed to be inadequate, since several studies highlighted the important hormonal role in metabolic homeostasis of anatomically reconstructed intestine [13, 19, 20-22, 27, 28].

Several mechanisms mediate the anti-diabetic impact of RYGB, including induced by restricted pouch and limited intestinal absorption lower caloric intake, hyper-stimulation of the distal ileum to pro- duction of incretins, compromised ghrelin secretion or, though credited to the fast postoperative glucose control, the still unidentified phenomenon related to duodenum exclusion from contact with ingested food $[13,14,29,30]$.

The fast improvement of glucose tolerance presented in this study (even during the hospital stay) confirms the effectiveness of the weight loss independent mechanisms reported previously by other researchers in both animal and human models [22, 31-33]. Approximately $40 \%$ of patients were discharged from hospital with the FPG level $\leq 100 \mathrm{mg} / \mathrm{dl}$ but this number was as high as $80 \%$ in other reports [13]. This rapid improvement was not observed after purely restrictive procedures, which emphasizes the exceptional impact of bypassed duodenum and proximal jejunum [9, 34-37]. The accelerated transmission of the undigested food to the distal ileum observed in BPD because of the ultra-short alimentary and long biliary limb alters the intensity of incretins (e.g. glucagon-like peptide-1) secretion, impacting beta-cell stimulation to insulin production and therefore influencing glycemia control $[13,18]$. Moreover, it was suggested that a long part of the intestine excluded from passage influences higher "recycling" of the undiluted bile, which additionally enhances the desired metabolic effect [14, 18, 29].

The short nutrients pathway and extended biliary limb is also constructed in the $\Omega$-loop gastric bypass, where the total length of excluded jejunum is localized proximally to the pouch-jejunum anastomosis. This variation of gastric bypass, popular in some bariatric centers, is considered by some authors as one of the most sufficient second-stage procedures after sleeve gastrectomy [38].

A higher T2DM remission rate was demonstrated in patients after gastric bypass modified with a longer biliary limb, but not with an elongated alimentary limb $[15,16]$. Clear-cut evidence of superiority of elongated BL modification over standard RYGB was 
reported recently by Pinheiro et al. [30]. To enhance the antidiabetic mechanism, this technical solution learned from BPD was partially adopted into RYGB also in our study, by extending the biliary limb from $50-80 \mathrm{~cm}$ to $135-150 \mathrm{~cm}$ without changing any other anatomical aspects of the procedure. In order to reduce the risk related to the high degree of malabsorption from too short common limb, the length of $\mathrm{CL}$ was set as described by many authors as safe at $150 \mathrm{~cm}[16,18]$.

In our study we observed a higher percentage of patients (free from anti-diabetic agents) in the L-BL group who achieved the laboratory non-diabetic criteria of $\mathrm{HbA}_{1 \mathrm{c}}$ and FPG values 3, 6, 12, 24 months after RYGB, than patients from the S-BL group. However, the average change in the value and $\Delta$ of diabetic markers did not differ significantly between the studied groups at any follow-up points. Analyzing the anatomical proportions of the intestine arranged in our procedures and considering the individual diversity of the intestinal length, we realized that elongating the $\mathrm{BL}$ in some of the patients led to the common limb shortening even below $200 \mathrm{~cm}$. An interesting finding of the study was that the length of $\mathrm{CL}$ strongly correlates with the metabolic effect of the surgery in both groups. A more significant effect of the surgery was observed in patients with shorter $\mathrm{CL}$.

The number of long-term adverse events was comparable in both groups and seemed to be more the consequence of complications than the longterm result of anatomical variations. The rate of the malnutrition burden was related to shorter $\mathrm{CL}$ but principally accompanied such complications as anastomosis strictures or prolonged gastrointestinal fistulas and was minimized by a strict postoperative monitoring schedule provided by a multidisciplinary team, which is recommended in several guidelines.

Episodes of postoperative hypoglycemia were experienced by nearly half of the operated patients in both groups, which corresponds with Schauer's observations, but still this phenomenon is less frequent than in the group of patients treated conservatively with insulin [9].

According to what has previously been investigated, the persistent effect of glucose metabolism improvement depends on the growth of insulin sensitivity mainly in peripheral tissues which occurs 6 months after duodenal bypass surgery with a peak 2 years after surgery [39]. This dynamic process is correlated with reduction of lipid content in the mus- cles or liver and is supposed to be proportional to weight loss [17, 40-42]. Moreover, this anti-diabetic mechanism is supplemented with over-stimulation of beta islets to endogenous insulin production $[14,43]$.

Providing the most intensive adipose tissue reduction, BPD is favored as the most effective bariatric procedure, which also influences the long-term glucose metabolism [44]. However, potentially serious malnutrition and relatively higher risk, mostly in patients whose compliance to the therapy is inadequate, may limit the indications to the superobese population of patients. Deriving the experiences from BPD, in the first place, bariatric surgeons should focus on common limb length in designing the gastric bypass procedure to obtain more durable benefits [16]. Long-term observations of patients after modified RYGB with extended biliary limb alone are required to estimate its effect in patients with T2DM. The combination of relevant lengths of the $B L$ and $C L$ in RYGB seems to be a promising solution which can reduce the necessity of more malabsorptive surgical arrangements such as BPD.

\section{Conclusions}

A longer biliary limb can intensify the anti-diabetic effect of RYGB. However, the length of the common limb rather than the biliary limb influences the laboratory T2DM remission in obese patients after RYGB. A long-term observational study is needed to fully assess whether introduced technical solutions in RYGB would provide a durable effect of T2DM resolution.

\section{References}

1. King $\mathrm{H}$, Aubert RE, Herman WH. Global burden of diabetes, 1995-2005: prevalence, numerical estimates and projections. Diabetes Care 1998; 21: 1414-31.

2. IDF Diabetes Atlas 2009, 2011

3. Rubino F, Kaplan LM, Schauer PR, Cummings D; the Diabetes Surgery Summit Delegates. The Diabetes Surgery Summit Consensus Conference. Recommendations for the evaluation and use of gastrointestinal surgery to treat T2DM. Ann Surg 2011; 251: 399-405.

4. Rubino F. Is type 2 diabetes operable intestinal disease? Diabetes Care 2008; 31 (Suppl. 2): 290-6.

5. Which surgical procedure should be carried out for T2DM. Presented at the IXth Meeting of the Surgical Continuing Education, University of Malaga, Malaga 17-19 February 2010.

6. Batsis JA, Sarr MG, Collazo-Clavell ML, et al. Cardiovascular risk after bariatric surgery for obesity. Am J Cardiol 2008; 102: 930-7. 
7. Buchwald $H$, Estok R, Fahrbach $\mathrm{K}$, et al. Weight and T2DM after bariatric surgery: systematic review and meta-analysis. Am J Med 2009; 122: 248-56.

8. Sjöström L, Narbro K, Sjöström CD, et al. Effects of bariatric surgery on mortality in Swedish obese subjects. N Engl J Med 2007; 357: 741-52.

9. Schauer PR, Kashyap SR, Wolski K, et al. Bariatric surgery vs. intensive medical therapy in obese patients with diabetes. N Engl J Med 2012; 366: 1567-77.

10. Mingrone G, Panuzi S, Gaetano A, et al. Bariatric surgery vs conventional medical therapy for type 2 diabetes. N Engl J Med 2012; 366: 1577-86.

11. Lebovitz H. Type 2 diabetes mellitus, current therapies and emergence of surgical options. Nat Rev 2011; 10: 1038.

12. Hussain A, Mahmood H, El-Hasani S. Can Roux-en-Y gastric bypass provide a lifelong solution for diabetes mellitus? Can J Surg 2009; 52: E269-75.

13. Thaler JP, Cummings DE. Hormonal and metabolic mechanisms of diabetes remission after gastrointestinal surgery. Endocrinology 2009; 150: 2518-25.

14. Dar MS, Chapman WH, Pender JR, et al. GLP-1 response to a mixed meal: what happens 10 years after Roux-en- $Y$ gastric bypass? Obes Surg 2012; 22: 1077-83.

15. Dellagrave G, Marchesini JC. End to side duodeno-jejunostomy with half-and-half biliopancreatic limb for the treatment of type 2 diabetes: a proposal for a simpler technique. Obes Surg 2007; 17: 138-9.

16. Stefanidis D, Kuwada TS, Gersin KS. The importance of the lengh of the limbs for gastric bypass - an evidence-based review. Obes Surg 2011; 21: 119-24.

17. Perugini RA, Malkani S. Remission of type 2 diabetes mellitus following bariatric surgery: review of mechanisms and presentation of the concept of reversibility. Curr Opin Endocrinol Diabetes Obes 2011; 18: 119-28.

18. Scopinaro N. Thirty-five years of BPD: notes on gastrointestinal physiology to complete the published information useful for better understanding and clinical use of the operation. Obes Surg 2012; 22: 427-32.

19. Gautier JF, Fetita S, Sobngwi E, Salaun-Martin C. Biological actions of incretins GIP and GLP-1 and therapeutic perspectives in patients with T2DM. Diabetes Metab 2005; 31: 233-42.

20. Mingrone G, Castagneto-Gissey L. Mechanism of early improvement/resolution of type 2 diabetes after bariatric surgery. Diabetes Metab 2009; 35: 518-23.

21. Rubino F, Schauer PR, Kaplan LM, Cummings DE. Metabolic surgery to treat type 2 diabetes: clinical outcomes and mechanism of action. Ann Rev Med 2010; 61: 393-411.

22. Rubino F, Forgione A, Cummings DE, et al. The mechanism of diabetes control after gastrointestinal bypass surgery reveals a role of the proximal small intestine in the pathophysiology of type 2 diabetes. Ann Surg 2006; 244: 741-9.

23. World Health Organization (2011) Health experts accept use of HbAlc for diagnosing diabetes. Geneva: WHO Diabetes Unit. Available at: www.who.int/diabetes

24. American Diabetes Association. Diagnosis and classification of diabetes mellitus. Diabetes Care 2009; 32: 62-6.

25. Buse JB, Caprio S, Cefalu WT, et al. How do we define cure of diabetes? Diabetes Care 2009; 32: 2133-5.
26. Proczko M, Kaska $Ł$, Kobiela J, et al. Roux-en-Y gastric bypass in dialysed morbidly obese patients as a preparation for a kidney transplantation: case series. Videosurgery Miniinv 2013; 8: 174-7.

27. Geloneze B, Geloneze SR, Fiori C, et al. Surgery for non-obese type 2 diabetic patients: an interventional study with duodenal-jejunal exclusion. Obes Surg 2009; 19: 1077-83.

28. Fried M, Ribaric G, Buchwald JN, et al. Metabolic surgery for the treatment of T2DM in patients with $\mathrm{BMI}<35 \mathrm{~kg} / \mathrm{m} 2$ : an integrative review of early studies. Obes Surg 2010; 20: 776-90.

29. Pattou F, Beraud G, Arnalsteen L, et al. Catering of insulinosecretion after gastric bypass in T2DM is independed from body weight loss and correlated to the increase of GLP1. Diabetes Metab 2008; 34: A23.

30. Pinheiro JS, Schiavon CA, Pereira PB, et al. Long-long limb Rouxen-Y gastric bypass is more efficacious in treatment of type 2 diabetes and lipid disorders in super-obese patients. Surg Obes Relat Dis 2008; 4: 521-5.

31. Rubino F, Marescaux J. Effect of duodenal-jejunal exclusion in non-obese animal model of T2DM: a new perspective for an old disease. Ann Surg 2004; 239: 1-11.

32. Bose M, Olivian B, Teixeira J, et al. Do incretins play a role in the remission of T2DM after gastric bypass surgery: what are the evidences? Obes Surg 2009; 19: 217-29.

33. Grueneberger JM, Fritz T, Zhou C, et al. Long segment ileal transposition leads to early amelioration of glucose control in the diabetic obese Zucker rat. Videosurgery Miniinv 2013; 8: 130-8.

34. Paluszkiewicz R, Kalinowski P, Wróblewski T, et al. Prospective randomized clinical trial of laparoscopic sleeve gastrectomy versus open Roux-en-Y gastrin bypass for the management of patients with morbid obesity. Videosurgery Miniinv 2012; 7 : 225-32.

35. Bužga M, Holéczy P, Švagera Z, et al. Effects of sleeve gastrectomy on parameters of lipid and glucose metabolism in obese women -6 months after operation. Videosurgery Miniinv 2013; 8: 22-8.

36. Visockiene Z, Brimas G, Abaliksta T, et al. Metabolic changes one year after laparoscopic adjustable gastric banding operation in morbidly obese subjects. Videosurgery Miniinv 2013; 8: 13-21.

37. Razak HH, Dadan J, Gołaszewski P, Safiejko K. Impact of laparoscopic sleeve gastrectomy on body mass index, ghrelin, insulin and lipid levels in 100 obese patients. Videosurgery Miniinv 2012; 7: 251-9.

38. Weiner R, Theodoridou S, Weiner S. Failure of laparoscopic sleeve gastrectomy - further procedure? Obes Facts 2011; 4 Suppl. 42-6.

39. Wickremesekera K, Miller G, Naotunne TD, et al. Loss of insulin resistance after Roux-en-Y gastric bypass surgery: a time course study. Obes Surg 2005; 15: 474-81.

40. Laferrere B, Teixeira J, McGinty J, et al. Effect of weight loss by gastric bypass surgery vs. hypocaloric diet on glucose and incretin levels in patients with type 2 diabetes. J Clin Endocrinol Metab 2008; 93: 2479-85.

41. Kadera BE, Lum K, Grant J, et al. Remission of type 2 diabetes after RYGB is associated with greater weight loss. Surg Obes Relat Dis 2009; 5: 305-9. 
42. Jastrzębska-Mierzyńska M, Ostrowska L, Razak HH, Dadan J. Assessment of dietary habits, nutritional status and blood biochemical parameters in patients prepared for bariatric surgery: a preliminary study. Videosurgery Miniinv 2012; 7: 156-65.

43. Hall TC, Pellen MG, Sedman PC, Jain PK. Preoperative factors predicting remission of type 2 diabetes mellitus after Roux-en-Y gastric bypass surgery for obesity. Obes Surg 2010; 20: 1245-50.

44. Prachand VN, Ward M, Alverdy JC. Duodenal switch provides superior resolution of metabolic comorbidities independent of weight loss the super obese (BMI $\geq 50 \mathrm{~kg} / \mathrm{m} 2)$ compared to gastric bypass. J Gastrointest Surg 2010; 14: 211-20.

Received: 15.03.2013, accepted: 10.08.2013. 